\title{
Chemotherapy-related Cardiomyopathy
}

\author{
Susan E Piper and Theresa A McDonagh
}

King's College London, The James Black Centre, London, UK; Kings College Hospital NHS Foundation Trust, London, UK

\begin{abstract}
Advances in chemotherapeutic agents have resulted in significantly improved cancer survival rates. Cardiac toxicity, however, has emerged as a leading cause of morbidity, both during and years after treatment. One of the most common manifestations of cardiotoxicity is that of heart failure and left ventricular systolic dysfunction. In this review, current opinions and guidelines in this field are discussed, with particular focus on the most common culprits, the anthracyclines, and the monoclonal antibody, trastuzumab.
\end{abstract}

\section{Keywords}

Heart failure, chemotherapy, anthracyclines, monoclonal antibodies, trastuzumab

Disclosure: The authors have no conflicts of interest to declare. No funding was received for the preparation of this manuscript. Acknowledgements: Susan E Piper has received chairperson and speaker fees from Servier Laboratories. Theresa A McDonagh has received honoraria for lectures and advisory boards for Merck, Novartis and Vifor. Susan E Piper and Theresa A McDonagh have received an unrestricted educational grant from Novartis for a research project. Received: 21 May 2015 Accepted: 23 July 2015 Citation: European Cardiology Review, 2015;10(1):19-24 Correspondence: Susan E Piper, Department of Cardiology, King's College Hospital, Denmark Hill, London SE5 9RS, UK. E: susanpiper@kcl.ac.uk

Support: The research was supported by the National Institute for Health Research (NIHR) Clinical Research Facility at Guy's \& St Thomas' NHS Foundation Trust and NIHR Biomedical Research Centre based at Guy's and St Thomas' NHS Foundation Trust and King's College London. The views expressed are those of the author(s) and not necessarily those of the NHS, the NIHR or the Department of Health.

Over the past 20 years, research and development in the field of oncology has produced significant changes and progress in cancer care. With the implementation of more aggressive cancer screening programmes, improvements in diagnostic testing and more effective treatment options, cancer death rates are gradually declining while cancer survivorship is steadily rising. ${ }^{1-3}$

Such statistics, however, have not been achieved without consequence, and are often offset by long-term adverse effects. While conventional chemotherapy has been known for decades to induce detrimental effects on the heart and peripheral vasculature, the use of novel agents are also increasingly being shown to have harmful off-target consequences to cardiac function. Thus, concurrent with advances in cancer therapies, so there has been a significant increase in cardiovascular side effects. ${ }^{4}$

One of the most common manifestations of cardiotoxicity associated with exposure to anticancer therapies is the development of left ventricular systolic dysfunction (LVSD) and overt heart failure (HF). As a result, the need for specialist cardiology input is becoming increasingly recognised as an important resource in the management of both longterm survivors and those undergoing active treatment. The aim of this paper is to review current opinions on the diagnosis, pathophysiology, management and prevention of chemotherapy-related cardiomyopathy, with specific focus on the commonest, and most studied culprits: the anthracyclines and monoclonal antibodies.

\section{Definition of Chemotherapy-induced Cardiomyopathy}

Despite the increasing recognition of chemotherapy-induced cardiomyopathy, consensus on international definitions in both clinical practice and trials remain lacking. Such definitions range from the development of HF symptoms, to the development of overt LV dysfunction and a reduction in ejection fraction (EF) on cardiac imaging (see Table 1). Indeed, the incidence of HF or LVSD in chemotherapy trials has been shown to range from 5 to $65 \%$ depending on the criteria used. ${ }^{5,6}$ Moreover, it is widely accepted that chemotherapyinduced LVSD is often sub-clinical in the early stages, with overt changes in LVEF occurring after only a significant level of damage has occurred. Nevertheless, currently, a change in LVEF remains the basis for all definitions of cardiotoxicity issued by scientific societies in both Europe and the US.7.8

\section{Anthracyclines}

Anthracyclines are widely used to treat a variety of haematological, soft-tissue and solid malignancies. Cardiac toxicity has been recognised as a complication of treatment since the 1970s, ${ }^{15,16}$ with presentations ranging from subclinical ventricular dysfunction to severe cardiomyopathy and overt HF. Classically, cardiac dysfunction is related to anthracycline therapy in an exponentially dose-dependent manner. The early incidence of HF and LVSD ranges from 1 to $16 \%$, with increasing incidence as time post treatment progresses. ${ }^{17-19}$ Consequently, childhood cancer survivors have a high risk of experiencing symptomatic cardiac events at an early age, and this risk remains high for at least 30 years, when almost one in eight will experience severe heart disease. $^{2}$

Pathophysiology of Anthracycline-related Cardiomyopathy The cardiotoxic effects of the anthracyclines are not completely understood. Several mechanisms have been proposed, with the most widely accepted theory being the formation of anthracycline-iron 
Table 1: Comparison of Different Definitions of Cardiotoxicity in Several Large Randomised Controlled Trials

\begin{tabular}{|c|c|c|}
\hline Study & $\begin{array}{l}\text { Chemotherapy } \\
\text { Agent }\end{array}$ & Definition \\
\hline Schwartz $1987^{9}$ & Doxorubicin & $\begin{array}{l}\text { Absolute } 10 \% \text { drop in LVEF or a } \\
\text { decrease to below } 50 \% \text { in patients } \\
\text { with baseline LVEF }>50 \% \text {, or an } \\
\text { absolute } 10 \% \text { drop in LVEF or a drop } \\
\text { below } 30 \% \text { in patients with baseline } \\
\text { LVEF }<50 \%\end{array}$ \\
\hline Slamon $2001^{10}$ & Trastuzumab & NYHA classification \\
\hline O'Brien 2004'11 & Anthracycline & $\begin{array}{l}\text { Decline in LVEF of } 20 \text { points to } \\
>50 \% \text { or at least } 10 \text { points to }<50 \% \\
\text { or clinical CHF }\end{array}$ \\
\hline $\begin{array}{l}\text { Tan-Chiu } \\
\text { (NSABP-31) } \\
2005^{12}\end{array}$ & Trastuzumab & Decline LVEF by $10 \%$ to $<55 \%$ \\
\hline Romond $2005^{13}$ & $\begin{array}{l}\text { Doxorubicin and } \\
\text { cyclophosphamide } \\
\text { followed by } \\
\text { trastuzumab }\end{array}$ & Decline of LVEF $>16 \%$ or $<$ LLN \\
\hline Ryberg $2008^{14}$ & Anthracycline & $\begin{array}{l}\text { Decline of LVEF }<45 \% \text { or } 15 \text { points } \\
\text { from baseline }\end{array}$ \\
\hline
\end{tabular}

CHF = congestive heart failure; $L L N=$ lower limit of normal; $N S A B P=$ National Adjuvant Breast and Bowel Project; NYHA = NeW York Heart Association

complexes and stimulation of free-radical formation. ${ }^{2,20-23}$ In support of this is the finding that iron-chelating compounds inhibit this toxic effect. ${ }^{24}$ Despite this being the preferred theory, it is by no means the only mechanism by which the anthracyclines are thought to cause myocardial damage. More recently, Zhang et al. ${ }^{25}$ have demonstrated that, in mouse studies, deletion of the enzyme Top2b (encoding topoisomerase- $\| \beta)$ in cardiac myocytes was protective against the doxorubicin-induced DNA double-strand breaks and transcription changes that are responsible for defective mitochondrial biogenesis and the formation of reactive oxygen species. Furthermore, this deletion protected against the development of doxorubicin-induced $\mathrm{HF}$, suggesting that doxorubicin-induced cardiotoxicity may be mediated by topoisomerase- $\| \beta$ in mammalian cardiomyocytes.

Other proposed cardiotoxic actions of anthracyclines include: decreased adenosine triphosphate production; formation of toxic metabolites; inhibition of nucleic acid and protein synthesis; release of vasoactive amines; impairment of mitochondrial membrane binding, assembly and creatine kinase activity; induction of apoptosis; disturbances in intracellular calcium homeostasis; induction of nitric oxide synthetase; increased cytochrome $\mathrm{C}$ release from mitochondria; and increases in immune functions. ${ }^{14,26,27}$

\section{Risk Factors for Anthracycline \\ Related Cardiomyopathy}

Perhaps the most predictive measure of the development of anthracycline-related cardiotoxicity is the total cumulative dose..$^{28,29}$ In a review of three prospective trials assessing the effect of doxorubicin, Swain et al. demonstrated an incidence of HF of $3 \%$ at a cumulative dose of $400 \mathrm{mg} / \mathrm{m}^{2}$, increasing to $7 \%$ and $18 \%$ at cumulative doses of $550 \mathrm{mg} / \mathrm{m}^{2}$ and $700 \mathrm{mg} / \mathrm{m}^{2}$, respectively. ${ }^{28}$ Combined with other treatment-related risk factors, such as additional cardiotoxic chemotherapeutic agents and radiotherapy, the incidence of HF is substantially increased..$^{10}$
Several patient-related factors have also been identified as markers of risk in the anthracycline-treated population. These range from genetic predisposition (female sex, Trisomy 21, African-American ancestry, ${ }^{28,30-32}$ and carriers of the haemochromatosis C282Y HFE gene mutation $\left.{ }^{33}\right)$, to recognised pre-existing cardiac risk factors such as extremes of age, prior ischaemic heart disease, valvular heart disease and, in particular, hypertension. ${ }^{34}$

\section{Prevention of Anthracycline-related Cardiomyopathy} A number of strategies and agents have been examined for potential use in preventing HF or LVSD related to anthracycline therapy, with varying levels of success. ${ }^{26,35-61}$ Such strategies include attempts to reduce peak plasma concentrations, prevention of iron-dependent free-radical formation ${ }^{52}$ and the use of evidence-based HF medications.

\section{Limitation of Peak Plasma Concentrations}

Several strategies have been examined to limit peak plasma concentrations, including the use of liposomal anthracycline preparations, novel synthetic anthracyclines and infusion versus bolus administration. Despite promising results in terms of maintained anti-cancer therapy, ${ }^{35-37}$ many strategies to limit peak plasma concentrations have either been limited by side effects ${ }^{44}$ or have not been associated with significant reductions in long-term risk of cardiomyopathy ${ }^{45,46,50,5,1,62,63}$ Most promising results have been with the use of liposomal preparations, with rates of cardiotoxicity being significantly lower compared with conventional preparations. ${ }^{36,37,64}$

\section{Iron Binding}

Dexrazoxane binds intracellular iron and prevents iron-dependent free-radical formation. ${ }^{52}$ Although initial results led to the approval of its use to prevent long-term cardiotoxicity in patients receiving doxorubicin or epirubicin, ${ }^{53,54}$ subsequent clinical trials reported cases of secondary leukaemia in children and adults.5,56

\section{Angiotensin Converting Enzyme Inhibitors, Beta-Blockers and Mineralocorticoid Receptor Antagonists}

Angiotensin converting enzyme inhibitors (ACE-I) and beta (B)-blocker therapy have both been shown to have protective effects against chemotherapy-induced HF or LVSD in both animal models and in adult patients with early toxicity. ${ }^{57-59}$ More recently, the results of the prevention of left ventricular dysfunction with Enalapril and caRvedilol in patients submitted to intensive Chemotherapy for the treatment of Malignant hEmopathies (OVERCOME) trial ${ }^{60}$ have demonstrated that, compared with those in the treatment arm, those in the control group had a significantly higher reduction in LVEF, incidence of death or HF at six-months follow-up ( $p=0.02)$. Less evidence exists for the use of mineralocorticoid receptor antagonists (MRAs). In one recently published small randomised controlled trial, Akpek et al. ${ }^{61}$ demonstrated preservation of LV systolic and diastolic function in the group treated with spironolactone prior to the initiation of chemotherapy at 6-months follow-up. Further studies are needed to corroborate these findings.

\section{Trastuzumab (Herceptin ${ }^{\circledR}$ )}

Trastuzumab is a monoclonal antibody used in the treatment of HER2+ breast cancer. It exerts its actions by blocking the HER2 epidermal growth factor receptor, which is overexpressed in approximately 15-20\% of breast tumours and associated with more aggressive disease. $.5,66$ Following phase III trials demonstrating significant improvements in both overall survival and risk of relapse, it was approved for clinical use in 1998. ${ }^{67}$ 
Introduction of trastuzumab into routine clinical practice, however, led to the unexpected finding of 'off-target' effects on the cardiovascular system. In one landmark trial, Slamon et al. demonstrated incidence rates of cardiac dysfunction of $27 \%$ and New York Heart Association (NYHA) class III/IV symptoms of $16 \%$ when trastuzumab was used in combination with both anthracyclines and cyclophosphamide. ${ }^{10}$

\section{Pathophysiology of Trastuzumab-related Cardiomyopathy}

The pathogenesis of trastuzumab cardiotoxicity is not completely understood, but appears to be related to blockage of HER2 receptor signals in cardiac myocytes - signalling that appears essential for cardiac myocyte repair. ${ }^{68}$

When given concurrently with anthracyclines, it has been proposed that the administration of anthracyclines results in initial oxidative damage to cardiac myocytes, resulting in those cells sustaining sufficient damage undergoing apoptosis or necrosis. The remaining injured myocytes undergo repair processes but remain temporarily vulnerable - the so-called 'vulnerable window hypothesis'.69 In the presence of trastuzumab, inhibition of the normally upregulated HER2 results in loss of the usual repair mechanisms, driving the myocytes to further apoptosis and necrosis. In support of this theory are the findings of later studies examining the use of sequential anthracyclines and trastuzumab therapy. In these trials, initiation of a 3-week interval between treatments resulted in a reduction in the incidence of NYHA class III/IV HF to $3.8 \% .^{12}$ With a longer 90-day interval, this reduced to just $0.6 \%$, with systolic dysfunction occurring in only $7 \%{ }^{70}$ compared with the $27 \%$ reported by Slamon et al. ${ }^{10}$

In most instances, HF or LVSD related to trastuzumab is a sub-acute phenomenon, with the majority of cases being observed during treatment. It does, however, appear to be reversible after drug withdrawal and does not appear to be dose dependent. ${ }^{4}$

Risk Factors for Trastuzumab-related Cardiomyopathy Apart from the well-recognised and documented risk in the setting of concurrent anthracycline therapy, risk factors for the development of trastuzumab-induced HF or LVSD are less well defined. In part, this is due to the exclusion of both older patients and those with 'traditional' risk factors for cardiac disease from clinical trials. Several retrospective cohort analyses have attempted to address this matter.68,71,72 Results suggest those with borderline lower limit of normal LVEF, history of heart disease or prior treatment with anti-hypertensive medication and those of advanced age have the highest risk of cardiotoxicity.

\section{Prevention of Trastuzumab-related Cardiomyopathy}

Few strategies have been adequately evaluated to determine their usefulness in preventing trastuzumab-induced HF or LVSD. Aside from delaying therapy until after treatment with anthracyclines is complete, possible strategies could include minimising trastuzumab treatment duration or the use of evidence-based HF medication.

Optimum duration for trastuzumab therapy remains unknown. Results from the Herceptin Adjuvant (HERA) trial comparing treatment over 12 and 24 months demonstrated no additional survival advantage with extended therapy, but did demonstrate continued risk of HF or LVSD. $^{73}$ The Protocol of Herceptin Adjuvant with Reduced Exposure (PHARE) trial compared six versus 12 months of trastuzumab and failed to show non-inferiority of the shorter treatment administration
Table 2: Reported Incidences of Cardiotoxicity in Other chemotherapeutic Agents

\section{Other Chemotherapy Agents}

\begin{tabular}{ll}
\hline Alkylating Agents & \\
$\begin{array}{l}\text { Cyclophosphamide } \\
\text { and Ifosfamide }\end{array}$ & Appear to have dose-dependent effects on \\
& cardiac myocytes. With doses $\geq 150 \mathrm{mg} / \mathrm{kg}$, \\
& cyclophosphamide has been associated with HF \\
& in 7-28\% of patients. Ifosfamide has been \\
& associated with HF in $17 \%$ of patients treated \\
& with doses $\geq 12.5 \mathrm{~g} / \mathrm{m}^{2} .4 .5$ \\
\hline
\end{tabular}

Microtubule Agents

Paclitaxel and docetaxal Both paclitaxel and docetaxel are widely used in the treatment of multiple malignancies, with relatively low incidences of $\mathrm{HF}$, estimated at $1.68 \%{ }^{79}$

\section{Proteosome Inhibitors}

Bortezomib. Used to treat multiple myeloma and mantle cell

(Velcade ${ }^{\circledR}$ lymphoma, incidence of HF and HF events has been estimated at $2-5 \% .{ }^{80}$

\begin{tabular}{ll}
\hline Small Molecule Tyrosine Kinase Inhibitors \\
\hline Lapatinib & Experience to date in a relatively small studied \\
& population suggests relatively low rates of \\
& symptomatic cardiac failure. In patients treated with \\
& prior anthracyclines, trastuzumab, or neither, the \\
& incidence of cardiac events was $2.2 \%, 1.7 \%$ and \\
& $1.5 \%$, respectively. ${ }^{81}$ \\
\hline Sunitinib & Initial reports of its use in renal cell carcinoma \\
& suggest a $10 \%$ incidence of asymptomatic drop \\
& in LVEF to $>10 \%$ of lower limit of normal, with full \\
& recovery when treatment was completed 82.
\end{tabular}

Monoclonal Antibody-based Tyrosine Kinase Inhibitors

Bevacizumab Incidence of HF ranges from $1.7 \%$ to $3 \%{ }^{4}$

$H F=$ heart failure; $L V E F=$ left ventricular ejection fraction.

but did demonstrate reduced incidence of cardiac events. ${ }^{74}$ Results from the Synergism or Long Duration (SOLD), ${ }^{75}$ Short-HER ${ }^{76}$ and PERSEPHONE ${ }^{77}$ trials are awaited to validate these findings.

No large randomised controlled trials have yet to report on the use of prognostically indicated HF medications to prevent HF or LVSD by trastuzumab. The Multidisciplinary Approach to Novel Therapies in Cardiology Oncology Research (MANTICORE) trial is due to address this issue by evaluating the efficacy of perindopril or bisoprolol for the prevention of LV remodelling in women with early breast cancer scheduled for chemotherapy and 1 year of trastuzumab.78

\section{Other Chemotherapy Agents}

Several other chemotherapy agents have also been associated with the development of heart failure (see Table 2), ${ }^{4,11,79-82}$

\section{Monitoring Cardiotoxicity of Chemotherapy}

\section{Cardiac Imaging}

Monitoring cardiac function for early disease is recommended for all cancer survivors exposed to cardiotoxic therapies. ${ }^{8,83}$ As a result of the different timings of presentation and potential for reversibility, algorithms proposed by the European Society of Medical Oncology (ESMO) for monitoring patients exposed to anthracycline or trastuzumab have been developed to reflect these differences. Most notably, guidelines for trastuzumab incorporate advice on continuation or discontinuation of therapy and allow for the presence of potentially reversible changes (see Figure 1). 
Figure 1: Algorithm for Continuation and Discontinuation of Trastuzumab Based on LVEF Assessments ${ }^{8}$

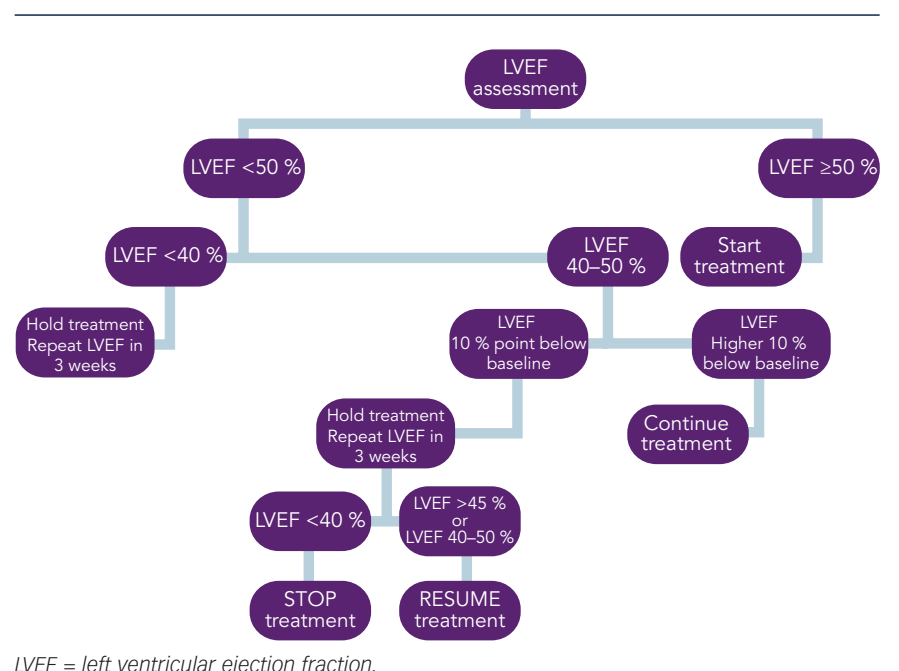

Figure 2: Algorithm for the Management of Cardiotoxicity in Patients Treated with Anthracyclines ${ }^{8}$

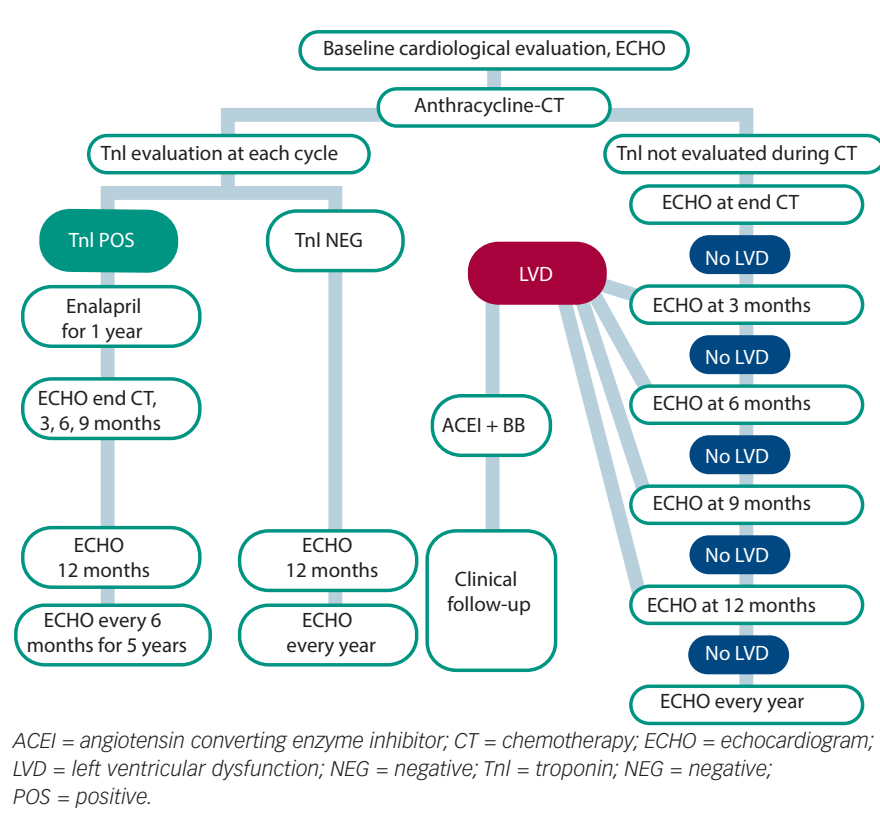

In recognition of the limitations of LVEF in detecting sub-clinical cardiotoxicity, several studies have examined the use of more sophisticated techniques, such as tissue velocity and strain imaging by echocardiography, and delayed contrast enhancement by cardiac magnetic resonance imaging (CMRI).

A recent meta-analysis of the use of myocardial strain imaging by echocardiography showed that, in late survivors of cancer, measures of global radial and circumferential strain are consistently abnormal, even in the context of normal LVEF. ${ }^{84}$ Their clinical value in predicting subsequent LVSD or HF, however, has yet to be fully explored, however, speckle tracking echocardiography (STE) and assessment of peak systolic global longitudinal strain (GLS) appears to be the most promising measure, with a 10-15\% early reduction in GLS by STE during therapy being predictive of cardiotoxicity.

Several studies have examined the use of CMRI and delayed contrast enhancement in the setting of chemotherapy-induced cardiotoxicity.
Figure 3: ESC Guidelines for the Management of LVSD100

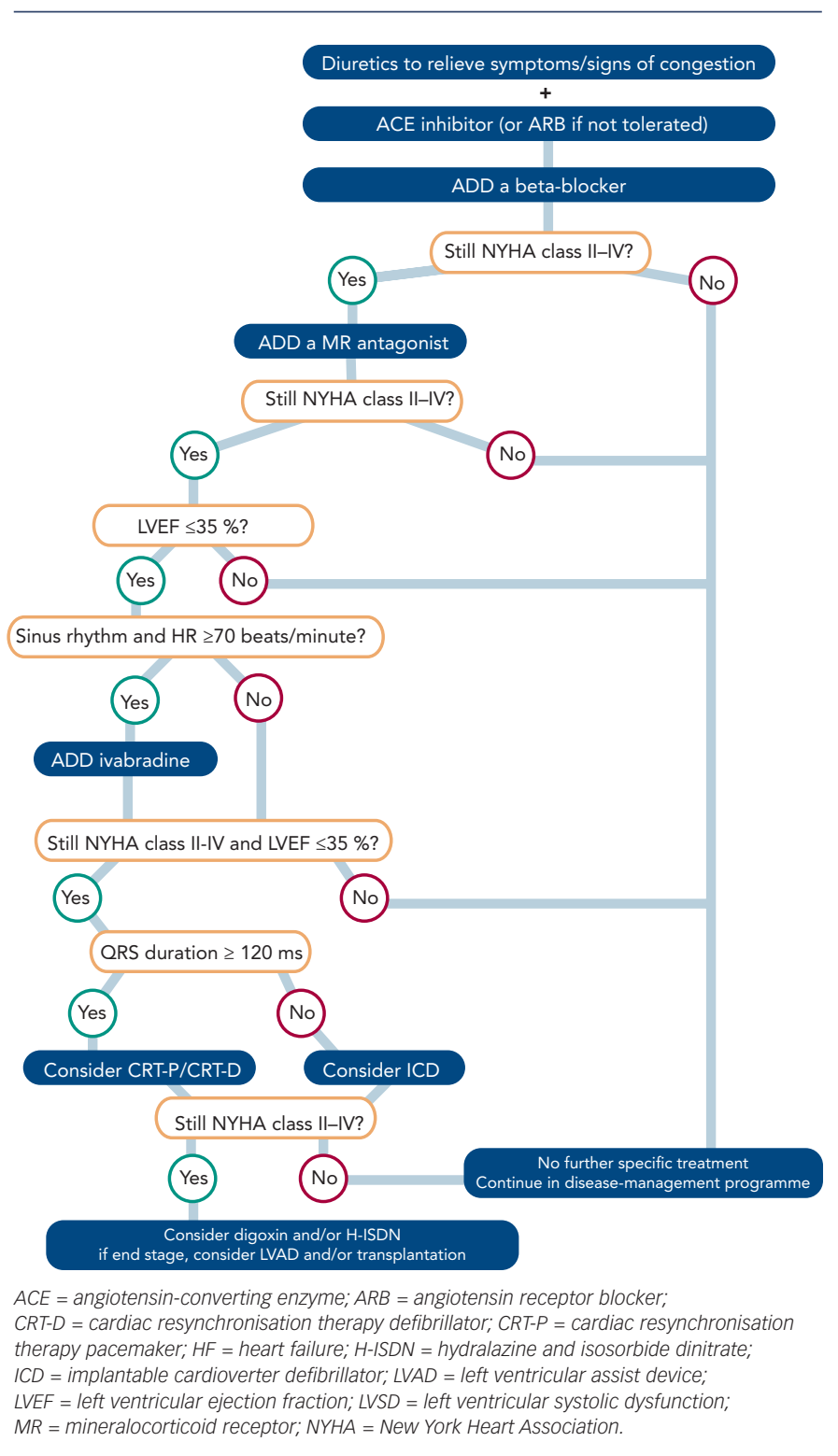

While no specific changes have been identified in the anthracycline population, trastuzumab has been associated with mid-wall delayed enhancement of the lateral wall. 85,86 Such findings have, however, only been reported in a small number of patients and further work is ongoing.

\section{Biomarkers}

Over the last two decades, data examining the use of biomarkers has demonstrated their measurement to be a more sensitive and specific tool for early identification; assessment and monitoring of chemotherapy-induced cardiac injury.

Several studies have reported on the use of cardiac troponins during anthracycline treatment and subsequent development of LV dysfunction. ${ }^{88,90-92}$ As a result, the latest guidance from ESMO has advocated the use of troponin in routine monitoring of patients undergoing anthracycline chemotherapy (see Figure 2). ${ }^{8}$ The use of troponins to identify patients at risk of trastuzumab-induced HF or LVSD is less well defined, but has been shown to identify those at risk of developing LVSD and, among them, those less likely to recover. ${ }^{69,93}$ 
A number of studies have looked at the use of the B-type natriuretic peptides, brain natriuretic peptide/N-terminal pro-brain natriuretic peptide (BNP and NTproBNP), in predicting LVSD in both anthracyclineand trastuzumab-induced cardiotoxicity, with mixed results. ${ }^{94-99}$ Consequently, current routine use of the natriuretic peptides for monitoring cardiotoxic effects of chemotherapy remains controversial.

\section{Treatment of Chemotherapy-induced Left Ventricular Systolic Dysfunction}

To date, no guidelines regarding the treatment of LVSD have been independently validated in the oncology setting. It is widely accepted, however, that once LVSD has ensued, treatment with evidence-based medications as per national and international guidelines should be instigated (see Figure 3). ${ }^{8,100,101}$

Of the evidence that does exist in the oncology setting, most has been based on treatment of anthracycline-related LVSD. In a study of 201 adult patients, Cardinale et al. demonstrated that LV dysfunction was potentially reversible but crucially depended on the time to treatment with ACE-I and B-blockers, supporting the need for serial monitoring. ${ }^{102}$

In contrast to LVSD secondary to anthracyclines, LVSD induced by trastuzumab is less well studied, but the initial data are promising. In a small study by Ewer, et al., ${ }^{103} 38$ patients with a diagnosis of trastuzumab-induced LVSD all patients demonstrated recovery of LV function. Thirty-two of these were temporally associated with medical therapy including ACE-I and B-blockers, with the remainder recovering without treatment. Of particular interest, 25 of those recovering after medical therapy were subsequently re-challenged with trastuzumab, with only three experiencing recurrence of LVSD. These results require confirmation in larger, randomised controlled trials but do indicate that monitoring may be a viable option for some patients with trastuzumabinduced cardiotoxicity and re-challenge may be 'safe'. Moreover, several studies have demonstrated that LVSD related to trastuzumab therapy appears to be reversible, with resolution of cardiac function in approximately $80 \%$ of cases seen in the majority of trials. ${ }^{73}$ As a result of these findings, guidelines from ESMO suggest that the introduction of prognostically indicated HF medication may not be required unless the LVEF is $<40 \%{ }^{8}$

\section{Conclusion}

Chemotherapy-related cardiotoxicity in the form of HF or LVSD is a serious 'off-target' side effect of several important chemotherapeutic agents. At present monitoring of cardiac function and intervention in the presence of deterioration is the mainstay of management, but it is widely acknowledged that earlier detection and intervention is required to improve longer-term prognosis. Advanced imaging techniques and the use of cardiac specific biomarkers may herald significant changes in our management of this condition. It is inevitable, however, that with continued advances in the field of oncology, the incidence of 'off-target' cardiac side effects will likely increase. Cross-specialty collaboration will undoubtedly be the key to ensuring the best care for cancer patients.
1. Yusuf SW, Cipolla C, Durand JB, Lenihan DJ, Cancer and cardiovascular disease. Cardiol Res Pract 2011:2011:943748. Jones RL, Ewer MS, Cardiac and cardiovascular toxicity of nonanthracycline anticancer drugs. Expert Rev Anticancer Ther 2006;6:1249-69.

3. Maddams J, Utley M, Moller H, Projections of cancer prevalence in the United Kingdom, 2010-2040. Br J Cancer 2012;107:1195-202.

4. Yeh ET, Bickford CL, Cardiovascular complications of cancer therapy: incidence, pathogenesis, diagnosis, and management. I Am Coll Cardiol 2009;53:2231-47.

5. Pai VB, Nahata MC, Cardiotoxicity of chemotherapeutic agents: incidence, treatment and prevention. Drug Saf 2000;22:263-302

6. Cardinale D, Colombo A, Cipolla CM, Prevention and treatment of cardiomyopathy and heart failure in patients receiving cancer chemotherapy. Curr Treat Options Cardiovasc Med 2008;10:486-95

7. Eschenhagen T, Force T, Ewer MS, et al., Cardiovascular side effects of cancer therapies: a position statement from the Heart Failure Association of the European Society of Cardiology. Eur I Heart Fail 2011;13:1-10.

8. Curigliano G, Cardinale D, Suter T, et al., Cardiovascular toxicity induced by chemotherapy, targeted agents and radiotherapy: ESMO Clinical Practice Guidelines. Ann Oncol 2012;23(Suppl. 7):viii155-66.

9. Schwartz RG, McKenzie WB, Alexander J, et al., Congestive heart failure and left ventricular dysfunction complicating doxorubicin therapy. Seven-year experience using serial radionuclide angiocardiography. Am J Med 1987;82:1109-18.

10. Slamon DJ, Leyland-Jones B, Shak S, et al., Use of chemotherapy plus a monoclonal antibody against HER2 for metastatic breast cancer that overexpresses HER2. N Eng/ J Med 2001;344:783-92.

11. O'Brien ME, Wigler N, Inbar M, et al., Reduced cardiotoxicity and comparable efficacy in a phase III trial of pegylated liposomal doxorubicin $\mathrm{HCl}$ (CAELYX/Doxil) versus conventional doxorubicin for first-line treatment of metastatic breast cancer. Ann Oncol 2004;15:440-9.

12. Tan-Chiu E, Yothers $G$, Romond E, et al., Assessment of cardiac dysfunction in a randomized trial comparing doxorubicin and cyclophosphamide followed by paclitaxel, with or without trastuzumab as adjuvant therapy in node-positive, human epidermal growth factor receptor 2-overexpressing breast cancer: NSABP B-31. I Clin Oncol 2005:23:7811-9.

13. Romond EH, Perez EA, Bryant J, et al., Trastuzumab plus adjuvant chemotherapy for operable HER2-positive breas cancer. N Engl J Med 2005;353:1673-84.

14. Ryberg M, Nielsen D, Cortese G, et al., New insight into epirubicin cardiac toxicity: competing risks analysis of 1097 breast cancer patients. I Natl Cancer Inst 2008;100:1058-67.
15. Lenaz L, Page JA, Cardiotoxicity of adriamycin and related anthracyclines. Cancer Treat Rev 1976;3:111-20.

16. Von Hoff DD, Rozencweig M, Layard M, et al., Daunomycininduced cardiotoxicity in children and adults. A review of 110 cases. Am J Med 1977:62:200-8.

17. Gilladoga AC, Manuel C, Tan CT, et al., The cardiotoxicity of adriamycin and daunomycin in children. Cancer 1976;37(Suppl. 2), 1070-8

18. Praga C, Beretta G, Vigo PL, et al., Adriamycin cardiotoxicity: survey of 1273 patients. Cancer Treat Rep 1979;63):827-34.

19. Bjorkhem G, Garwicz S, Echocardiographic assessment of le ventricular function during the injection of adriamycin. Acta Paediatr Scand 1977:66:595-600

20. Gewirtz DA, A critical evaluation of the mechanisms of action proposed for the antitumor effects of the anthracycline antibiotics adriamycin and daunorubicin. Biochem Pharmacol 1999;57:727-41.

21. Horenstein MS, Vander Heide RS, L'Ecuyer TJ, Molecular basis of anthracycline-induced cardiotoxicity and its prevention. Mol Genet Metab 2000;71(1-2), 436-44.

22. Hershko C, Link G, Tzahor M, Pinson A, The role of iron and iron chelators in anthracycline cardiotoxicity. Leuk Lymphoma 1993:11(3-4), 207-14.

23. Link $G$, Tirosh $R$, Pinson $A$, Hershko $C$, Role of iron in the potentiation of anthracycline cardiotoxicity: identification of heart cell mitochondria as a major site of iron-anthracycline interaction. J Lab Clin Med 127(3), 272-278 (1996).

24. Hershko C, Pinson A, Link G: Prevention of anthracycline cardiotoxicity by iron chelation. Acta haematologica $1996 ; 95: 87-92$

25. Zhang S, Liu X, Bawa-Khalfe T, et al., Identification of the molecular basis of doxorubicin-induced cardiotoxicity. Nat Med 2012;18:1639-42.

26. Wouters KA, Kremer LC, Miller TL et al, Protecting against anthracycline-induced myocardial damage: a review of the most promising strategies. Br I Haematol 2005;131:561-78.

27. Kalyanaraman B, Joseph J, Kalivendi S, et al., Doxorubicininduced apoptosis: implications in cardiotoxicity. Mol Cell Biochem 2002 May-Jun;234-235(1-2):119-24.

28. Swain SM, Whaley FS, Ewer MS, Congestive heart failure in patients treated with doxorubicin: a retrospective analysis of three trials. Cancer 2003;97:2869-79.

29. Von Hoff DD, Layard MW, Basa P, et al., Risk factors for doxorubicin-induced congestive heart failure. Ann Intern Med 1979:91:710-7.

30. Lipshultz SE, Colan SD, Gelber RD, et al., Late cardiac effects of doxorubicin therapy for acute lymphoblastic leukemia in childhood. N Eng/ I Med 1991;324:808-15.

31. Krischer JP, Epstein S, Cuthbertson DD, et al., Clinica cardiotoxicity following anthracycline treatment for childhood cancer: the Pediatric Oncology Group experience. J Clin Oncol 1997:15:1544-52.
32. Adams MJ, Lipshultz SE, Pathophysiology of anthracyclineand radiation-associated cardiomyopathies: implications for screening and prevention. Pediatr Blood Cancer 2005:44:600-606

33. Lipshultz SE, Lipsitz SR, Kutok JL, et al., Impact of hemochromatosis gene mutations on cardiac status in doxorubicin-treated survivors of childhood high-risk leukemia. Cancer 2013;119(19), 3555-62.

34. Barry E, Alvarez JA, Scully RE, et al., Anthracyclineinduced cardiotoxicity: course, pathophysiology, prevention and management. Expert Opin Pharmacother 2007:8:1039-1058.

35. Alberts DS, Muggia FM, Carmichael J, et al., Efficacy and safety of liposomal anthracyclines in phase $1 / / 1$ clinical trials. Semin Oncol 2004:31 (6 Suppl. 13), 53-90.

36. Batist G, Harris L, Azarnia N, et al., Improved anti-tumor response rate with decreased cardiotoxicity of non-pegylated posomal doxorubicin compared with conventional doxorubicin in first-line treatment of metastatic breast cancer in patients who had received prior adjuvant doxorubicin: results of a retrospective analysis. Anticancer Drugs 2006:17:587-95.

37. Safra T, Cardiac safety of liposomal anthracyclines. Oncologist 2003:8(Suppl. 2)17-24

38. Conklin KA, Coenzyme q10 for prevention of anthracyclineinduced cardiotoxicity. Integr Cancer Ther 2005:40,110-30.

39. Emanuelov AK, Shainberg A, Chepurko Y, et al., Adenosine A3 receptor-mediated cardioprotection against doxorubicininduced mitochondrial damage. Biochem Pharmacol 2010;79:180-7

40. Fu P, Arcasoy MO, Erythropoietin protects cardiac myocytes against anthracycline-induced apoptosis. Biochem Biophys Res Commun 2007:354:372-8.

41. Gebbia N, Flandina C, Leto G, et al., The role of histamine in doxorubicin and teniposide-induced cardiotoxicity in dog and mouse Tumori 1987:73:279-87.

42. Van Dalen EC, Caron HN, Dickinson HO, Kremer LC, Cardioprotective interventions for cancer patients receiving anthracyclines. Cochrane Database Syst Rev 2011;Cd003917.

43. Williams CJ, Doxorubicin cardiotoxicity: role of digoxin in prevention. BMJ 1978;1:176.

44. Rivankar S, An overview of doxorubicin formulations in cancer therapy. J Cancer Res Ther 2014;10:853-8.

45. Lahtinen R, Kuikka J, Nousiainen T, et al., Cardiotoxicity of epirubicin and doxorubicin: a double-blind randomized study. Eur I Haematol 1991:46:301-5.

46. Robert J, Rigal-Huguet F, Hurteloup P, Comparative pharmacokinetic study of idarubicin and daunorubicin in leukemia patients. Hematol Oncol 1992;10(),111-6.

47. Casper ES, Gaynor JJ, Hajdu SI, et al., A prospective randomized trial of adjuvant chemotherapy with bolus versus continuous infusion of doxorubicin in patients with high-grade extremity soft tissue sarcoma and an analysis of prognostic factors. Cancer 1991;68:1221-9. 
48. Hortobagyi GN, Frye D, Buzdar AU, et al., Decreased cardiac toxicity of doxorubicin administered by continuous intravenous infusion in combination chemotherapy for metastatic breast carcinoma. Cancer 1989;63:37-45.

9. Shapira J, Gotfried M, Lishner M, Ravid M: Reduced cardiotoxicity of doxorubicin by a 6-hour infusion regimen. A prospective randomized evaluation. Cancer 1990;65:870-3.

50. Lipshultz SE, Giantris AL, Lipsitz SR, et al., Doxorubicin administration by continuous infusion is not cardioprotective: the Dana-Farber 91-01 Acute Lymphoblastic Leukemia protocol. I Clin Oncol 2002:20:1677-82.

51. Lipshultz SE, Miller TL, Lipsitz SR, et al., Continuous versus bolus infusion of doxorubicin in children with ALL: Long-term cardiac outcomes. Pediatrics 2012;130:1003-11.

52. Cvetkovic RS, Scott $L$, Dexrazoxane: a review of its use fo cardioprotection during anthracycline chemotherapy. Drugs 2005;65:1005-24.

53. Testore F, Milanese S, Ceste M, et al., Cardioprotective effect of dexrazoxane in patients with breast cancer treated with anthracyclines in adjuvant setting: a 10-year single institution experience. Am I Cardiovasc Drugs 2008;8:257-63.

54. Venturini M, Michelotti A, Del Mastro $L$, et al., Multicenter randomized controlled clinical trial to evaluate cardioprotection of dexrazoxane versus no cardioprotection in women receiving epirubicin chemotherapy for advanced breast cancer. I Clin Oncol 1996;14:3112-20.

55. Research CFDEA: Drug Safety and Availability - FDA Statement on Dexrazoxane. Available at: http://www.fda.gov/ Drugs/Drugsafety/ucm263729.htm (accessed 8 July 2015).

56. Tebbi CK, London WB, Friedman D, et al., Dexrazoxaneassociated risk for acute myeloid leukemia/myelodysplastic syndrome and other secondary malignancies in pediatric Hodgkin's disease I Clin Oncol 2007:25:493-500.

57. Cardinale D, Colombo A, Sandri MT, et al., Prevention of high-dose chemotherapy-induced cardiotoxicity in highrisk patients by angiotensin-converting enzyme inhibition. Circulation 2006;114:2474-2481

58. Spallarossa P, Garibaldi S, Altieri P, et al., Carvedilol prevents doxorubicin-induced free radical release and apoptosis in cardiomyocytes in vitro. I Mol Cell Cardiol 2004;37:837-46.

59. Kalay N, Basar E, Ozdogru I, et al., Protective effects of carvedilol against anthracycline-induced cardiomyopathy. J Am Coll Cardiol 2006:48:2258-62.

60. Bosch X, Rovira M, Sitges M, et al. Enalapril and carvedilo for preventing chemotherapy-induced left ventricular systolic dysfunction in patients with malignant hemopathies: the OVERCOME trial (prevention of left Ventricular dysfunction with Enalapril and caRvedilol in patients submitted to intensive Chemotherapy for the treatment of Malignant hEmopathies). J Am Coll Cardiol 2013;61:2355-62.

61. Akpek M, Ozdogru I, Sahin O, et al., Protective effects of spironolactone against anthracycline-induced cardiomyopathy. Eur J Heart Fail 2015:17:81-9.

62. Anderlini P, Benjamin RS, Wong FC, et al., Idarubicin cardiotoxicity: a retrospective study in acute myeloid leukemia and myelodysplasia. I Clin Oncol 1995; 13:2827-34.

63. Creutzig U, Ritter J, Zimmermann M, et al., Idarubicin improves blast cell clearance during induction therapy in children with AML: results of study AML-BFM 93. AML-BFM Study Group. Leukemia 2001;15:348-54.

64. Harris L, Batist $\mathrm{G}$, Belt R, et al., Liposome-encapsulated doxorubicin compared with conventional doxorubicin in a randomized multicenter trial as first-line therapy of metastatic breast carcinoma. Cancer 2002:94:25-36.

65. Pegram M, Slamon D, Biological rationale for HER2/neu (c-erbB2) as a target for monoclonal antibody therapy. Semin Oncol 2000;27(5 Suppl. 9), 13-19.

66. Baselga J, Albanell J: Mechanism of action of anti-HER2 monoclonal antibodies. Ann Oncol ESMO 2001;12(Suppl. 1), S35-41.

67. Research CFDEA: Therapeutic Biologic Applications (BLA) Trastuzumab Product Approval Information - Licensing Action 9/25/98, 1998.

68. Crone SA, Zhao YY, Fan $L$, et al., ErbB2 is essential in the prevention of dilated cardiomyopathy. Nat Med 2002;8:459-65.
69. Morris PG, Chen C, Steingart R, et al., Troponin I and $C$-reactive protein are commonly detected in patients with breast cancer treated with dose-dense chemotherapy incorporating trastuzumab and lapatinib. Clin Cancer Res 2011:17:3490-9.

70. Piccart-Gebhart MJ, Procter M, Leyland-Jones B, et al., Trastuzumab after adjuvant chemotherapy in HER2-positive breast cancer. N Engl J Med 2005;353:1659-72.

71. Gunaldi $\mathrm{M}$, Duman BB, Afsar $\mathrm{CU}$, et al., Risk factors for developing cardiotoxicity of trastuzumab in breast cancer patients: An observational single-centre study. J Oncol Pharm Pract 2015 [Epub ahead of print].

72. Naumann D, Rusius V, Margiotta C, et al., Factors predicting trastuzumab-related cardiotoxicity in a real-world population of women with HER2+ breast cancer. Anticancer Res 2013;33:1717-20

73. De Azambuja E, Procter MJ, Van Veldhuisen DJ, et al , Trastuzumab-associated cardiac events at 8 years of median follow-up in the Herceptin Adjuvant trial (BIG 1-01). I Clin Oncol 2014;32:2159-65

74. Pivot $\mathrm{X}$, Romieu $\mathrm{G}$, Debled $\mathrm{M}$, et al., 6 months versus 12 months of adjuvant trastuzumab for patients with HER2positive early breast cancer (PHARE): a randomised phase 3 trial. Lancet Oncology 2013;14:741-8.

75. Clinicaltrials. Gov: The Synergism Or Long Duration (SOLD) Study. Available at: https://clinicaltrials.gov/ct2/show/ NCT00593697 (accessed 8 July 2015).

76. Guarneri V, Frassoldati A, Bruzzi P, et al., Multicentric, randomized phase III trial of two different adjuvant chemotherapy regimens plus three versus twelve months of trastuzumab in patients with HER2- positive breast cancer (Short-HER Trial; NCT00629278). Clin Breast Cancer 2008:8:453-6.

77. Clinicaltrials.Gov: Trastuzumab in Treating Women With HER2Positive Early Breast Cancer. Available at: https://clinicaltrials gov/ct2/show/NCT00712140 (accessed 8 July 2015).

78. Pituskin E, Haykowsky M, Mackey JR, et al., Rationale and design of the Multidisciplinary Approach to Novel Therapies in Cardiology Oncology Research Trial (MANTICORE 101--Breast): a randomized, placebo-controlled trial to determine if conventional heart failure pharmacotherapy can prevent trastuzumab-mediated left ventricular remodeling among patients with HER2+ early breast cancer using cardiac MRI. BMC Cancer 2011;11:318.

79. Marty M Cognetti F Maraninchi D, et al. Randomized phase trial of the efficacy and safety of trastuzumab combined with docetaxel in patients with human epidermal growth factor receptor 2-positive metastatic breast cancer administere as first-line treatment: the M77001 study group. I Clin Oncol 2005;23:4265-74

80. Richardson PG, Sonneveld P, Schuster MW, et al., Bortezomib or high-dose dexamethasone for relapsed multiple myelom N Engl J Med 2005;352:2487-98.

81. Perez EA, Koehler M, Byrne J, et al., Cardiac safety of lapatinib: pooled analysis of 3689 patients enrolled in clinica trials. Mayo Clinic proceedings 2008;83:679-86.

82. Schmidinger M, Zielinski CC, VogI UM, et al., Cardiac toxicity of sunitinib and sorafenib in patients with metastatic renal cell carcinoma. J Clin Oncol 2008;26:5204-12.

83. Lipshultz SE, Adams MJ, Colan SD, et al., Long-term cardiovascular toxicity in children, adolescents, and young adults who receive cancer therapy: pathophysiology, course, monitoring, management, prevention, and research directions: a scientific statement from the American Heart Association. Circulation 2013:128:1927-95.

84. Thavendiranathan P, Poulin F Lim KD et al Use of myocardial strain imaging by echocardiography for the early detection of cardiotoxicity in patients during and after cancer chemotherapy: a systematic review. J Am Coll Cardiol 2014;63(25 Pt A):2751-68.

85. Fallah-Rad N, Lytwyn M, Fang T, et al., Delayed contras enhancement cardiac magnetic resonance imaging in trastuzumab induced cardiomyopathy. I Cardiovasc Magn Reson 2008:10:5

86. Fallah-Rad N, Walker JR, Wassef A, et al., The utility of cardiac biomarkers, tissue velocity and strain imaging and cardiac magnetic resonance imaging in predicting early left ventricular dysfunction in patients with human epidermal growth factor receptor II-positive breast cancer treated with adjuvant trastuzumab therapy. I Am Coll Cardio 2011;57:2263-70

87. Tian S, Hirshfield KM, Jabbour SK, et al., Serum biomarkers for the detection of cardiac toxicity after chemotherapy and radiation therapy in breast cancer patients. Front Oncol 2014:4:277.

88. Cardinale D, Sandri MT, Colombo A, et al., Prognostic value of troponin I in cardiac risk stratification of cancer patients undergoing high-dose chemotherapy. Circulation 2004:109:2749-54

89. Dolci A, Dominici R, Cardinale D, et al., Biochemical markers for prediction of chemotherapy-induced cardiotoxicity: systematic review of the literature and recommendations for use. Am I Clin Pathol 2008;130:688-95.

90. Herman EH, Zhang J, Lipshultz SE, et al., Correlation between serum levels of cardiac troponin- $T$ and the severity of the chronic cardiomyopathy induced by doxorubicin. J Clin Onco 1999;17:2237-43.

91. Morandi P, Ruffini PA, Benvenuto GM, et al., Serum cardiac troponin I levels and ECG/Echo monitoring in breast cancer patients undergoing high-dose (7 g/m(2)) cyclophosphamide. Bone Marrow Transplant 2001:28:277-82.

92. Specchia G, Buquicchio C, Pansini N, et al., Monitoring of cardiac function on the basis of serum troponin I levels in patients with acute leukemia treated with anthracyclines. J Lab Clin Med 2005;145:212-20

93. Cardinale D, Colombo A, Torrisi R, et al., Trastuzumab-induced cardiotoxicity: clinical and prognostic implications of troponin I evaluation. J Clin Oncol 2010;28:3910-6.

94. Aggarwal S, Pettersen MD, Bhambhani K, et al., B-type natriuretic peptide as a marker for cardiac dysfunction in anthracycline-treated children. Pediatr Blood Cancer 2007;49:812-6.

95. Lipshultz SE, Miller TL, Scully RE, et al., Changes in cardiac biomarkers during doxorubicin treatment of pediatric patients with high-risk acute lymphoblastic leukemia: associations with long-term echocardiographic outcomes. Clin Oncol 2012;30:1042-9.

96. Sandri MT, Salvatici M, Cardinale D, et al., N-terminal proB-type natriuretic peptide after high-dose chemotherapy: a marker predictive of cardiac dysfunction? Clin Chem 2005:51:1405-10

97. Suzuki T, Hayashi D, Yamazaki T, et al., Elevated B-type natriuretic peptide levels after anthracycline administration. Am Heart J 1998;136:362-3.

98. Sawaya H, Sebag IA, Plana JC, et al., Assessment of echocardiography and biomarkers for the extende prediction of cardiotoxicity in patients treated with anthracyclines, taxanes, and trastuzumab. Circ Cardiovase Imaging 2012;5:596-603.

99. Daugaard G, Lassen U, Bie P, et al., Natriuretic peptides in the monitoring of anthracycline induced reduction in left ventricular ejection fraction. Eur \& Heart Fail 2005; 7:87-93.

100. McMurray JJ, Adamopoulos S, Anker SD, et al., ESC guidelines for the diagnosis and treatment of acute and chronic heart ailure 2012: The Task Force for the Diagnosis and Treatment of Acute and Chronic Heart Failure 2012 of the European Society of Cardiology. Developed in collaboration with the Heart Failure Association (HFA) of the ESC. Eur J Heart Fail 2012:14:803-69.

101. Yancy CW, Jessup M, Bozkurt B, et al, 2013 ACCF/AHA Guideline for the Management of Heart Failure: A Report of the American College of Cardiology Foundation/American Heart Association Task Force on Practice Guidelines. Circulation, 2013;128:1810-52.

102. Cardinale D, Colombo A, Lamantia G, et al., Anthracyclineinduced cardiomyopathy: clinical relevance and response to pharmacologic therapy. J Am Coll Cardiol 2010;55:213-20.

103. Ewer MS, Vooletich MT, Durand JB, et al., Reversibility of trastuzumab-related cardiotoxicity: new insights based on clinical course and response to medical treatment. I Clin Oncol 2005;23:7820-6. 